\title{
International Sports Law Journal (2013) 13:3-4
}

\author{
Jack Anderson
}

Published online: 9 October 2013

(C) T.M.C. Asser Instituut 2013

In a sports law sense, 2013 has been dominated by four issues; the governance of cycling; developments at the Court of Arbitration for Sport; sports-related gambling and betting regulation and, of course, the buying and selling of footballers. All four issues, amongst others, are debated and analysed in this issue of the International Sports Law Journal. The articles speak for themselves in terms of the breadth and depth of their scholarship and all this editorial proposes to do is to provide some background.

The governance of cycling is topical. At the time of writing the current president of the International Cycling Union (UCI), Pat McQuaid, is facing a forceful challenge for the UCI presidency by British cycling's chairman, Brian Cookson. A dispute has arisen as to whether McQuaid should be permitted to put his name forward for re-election despite not being nominated by his home federation, Ireland, or the federation where he currently resides, Switzerland. McQuaid has been nominated by other jurisdictions (Thailand and Morocco), but would need the UCI congress (to be held in Florence on 27 September) to ratify a change to the UCI constitution to allow this "extra-territorial" nomination to be deemed valid.

The level of disquiet in cycling is such that a number of leading jurisdictions, led by USA Cycling, have reportedly sought to engage the Court of Arbitration for Sport (CAS) in order to resolve the nomination dispute prior to the UCI Congress.

There is no doubt that the image of cycling has taken a severe battering over the past number of years. Most of this has been self-inflicted and relates to the revelations on the

J. Anderson ( $\square)$

Belfast, UK

e-mail: jack.anderson@qub.ac.uk engrained doping ethos in the professional sport. Radical solutions have been suggested from a truth commission to a "breakaway" organisation.

As for CAS, it continues to act effectively as the international court of justice for sport. In March 2013, amendments were introduced into the CAS Code of SportsRelated Arbitration. These amendments range from the general (the word "impartiality" has been added in all provisions where the independence of the CAS and its members is concerned); to the specific (it is now possible for a party to request interim measures from CAS immediately after the notification of a final decision by a sports federation but before the filing of a formal appeal at the CAS); and to amendments that might be deemed "futuristic" in nature (changes have been made in anticipation of the possible future creation of separate lists of arbitrators specialised in certain areas).

As regards cases law, the most noteworthy cases have been those relating to match-fixing suspensions. Under expedited procedural timetables, CAS has, pursuant to decisions made by UEFA, excluded football clubs such as Fenerbahce SK, Besiktas JK (both from Turkey) and FC Metalist Kharkiv (Ukraine) from UEFA club competitions for periods of time ranging from one to two seasons.

Many lessons will be drawn from the stated case law though it remains clear that the most effective, preventative response to match-fixing's integrity threat to sport is the proper regulation of betting both nationally and internationally.

Again at the time of writing, the summer football transfer window in Europe has come to an end. Or more relevantly, the window has been smashed. In England, total spending during the summer transfer window reached $€ 750$ million, a new record. The previous record was $€ 600$ million in 2008. The spending seems to have been 
fuelled by the first tranche of the Premier League's latest TV rights deal. In Italy's Serie A and in Spain's La Liga (featuring a world record player fee of $€ 100$ million paid by Real Madrid for Gareth Bale) the gross spend was a combined $€ 800$ million. Adding in France's Ligue 1 ( $€ 375$ million) and the German Bundesliga's $€ 275$ million, and the total in the five leading football league's in Europe equalled $€ 2$ billion.

At a micro-level, many of these transfers have repercussions in terms of training compensation, utility and solidarity payments. At a macro-level, it begs the question-whither Financial Fair Play?

Finally, and as ever in the preparation of the ISLJ, I thank the Managing Editor, Karen Jones, for her work in the production of this issue. I also have to express my sincere gratitude to the unseen work of our panel of "blind" reviewers. The task is a relatively thankless one for them and I thank them sincerely for the professionalism and promptness in dealing with the editorial team's requests. More broadly, we have endeavoured over the past number of months to put in place a double-blind, peer review system for the journal. This has been designed to produce the type of scholarship that the emerging discipline of sports law deserves. All potential referees are welcome!!

As ever, I look forward to any thoughts you might have on the future direction of the ISLJ; for now, I hope that you enjoy the current issue. 